\title{
A CRIAÇÃO DO DIREITO DO COMÉRCIO INTERNACIONAL: uma uniformização \\ desuniforme
}

\author{
Patricia Sampaio Fiad ${ }^{1}$
}

\begin{abstract}
RESUMO
Dado o crescente número de grupos de interesse atuantes no âmbito do comércio internacional, verifica-se uma diversidade de fontes do Direito do Comércio Internacional. O presente trabalho estuda os três principais vetores de criação deste ramo, de modo a analisar o quanto uniforme é esta criação. Primeiramente, averígua-se o papel das organizações internacionais especializadas em criar normas uniformes sobre comércio internacional e temas a fins. Essas organizações, por vezes privadas, por vezes compostas apenas por Estados, funcionam não apenas como uma fonte de Direito, mas também como fórum de debate entre os Estados. Posteriormente, verifica-se a função interpretativa e harmoniosa das cortes arbitrais, novamente, especializadas no tema em tela. Por fim, estuda-se, talvez, o principal vetor é a própria lex mercatoria traduzida como conjunto de princípios criados pelos agentes econômicos no mercado internacional. Este conjunto de princípios tem importância para comércio interfronteiriço desde seu surgimento, na Idade Média, e ganha destaque, no presente trabalho, quanto a sua conciliação com o Direito estatal. Desta forma, conclui-se que a atuação de diferentes fóruns e agentes econômicos que vão desde o Estado à empresa transnacional, numa complexa rede de interesses diversos, se traduz no Direito do Comércio Internacional.
\end{abstract}

PALAVRAS-CHAVE: Direito do Comércio Internacional. Direito Uniforme. Direito Comparado. Organização Internacional.

\section{THE CREATION OF INTERNATIONAL COMMERCIAL LAW: a desuniform uniformization}

\begin{abstract}
Given the increasing number of interest groups active in international trade, there is a diversity of sources of International Trade Law. This paper studies the three main vectors of the creation of this branch in order to examine how uniform is this creation. Firstly, it is analyzed the function of the international organizations specialized in creating uniform rules on international trade issues and purposes. These organizations, sometimes private, sometimes composed only of States, is not only a source of law, but also a forum for discussion among States. Later, it is verified the interpreting and harmonizing function of arbitration courts, again, specialized in the subject at hand. Finally, it is
\end{abstract}

\footnotetext{
${ }^{1}$ Bacharel em Direito pela UERJ e mestranda em Direito Internacional pela UERJ.. Artigo recebido em 19/07/2011 e aprovado em 05/10/2011
} 
studied, perhaps, the main vector is translated own lex mercatoria as a set of principles devised by the economic agents in the international market. This set of principles is important for international trade since its emergence in the Middle Ages, and gained prominence in the present work, as to reconcile them with the State Law. Thus, we conclude that the performance of different forums and economic agents ranging from the State to the transnational company, in a complex network of diverse interests, reflected in the International Trade Law.

KEY-WORDS: International Commercial Law, Uniform Law, Comparative Law, International Organization.

\section{A criação do Direito do Comércio Internacional: uma uniformização desuniforme}

A história da uniformização do Direito Comercial inicia-se no Renascimento, em que foi preciso enfrentar uma Europa dividida em pequenos feudos fechados em suas próprias atividades agrícolas, sem qualquer atividade comercial entre eles. Com o Renascimento e o crescimento das cidades italianas mercantis, passou-se a utilizar, no mercado europeu, o que hoje é chamada lex mercatoria. Segundo Irineu Strenger (STRENGER, 2005), Goldman define a lex mercatoria como sendo "precisamente um conjunto de princípios, instituições e regras com origem em várias fontes, que nutriu e ainda nutre estruturas e o funcionamento legal específico da coletividade de operadores do comércio internacional".

Assim como no passado, o mercado atualmente busca mecanismos legais eficientes na regulamentação do Direito do Comércio Internacional através da uniformização de normas mercantis. Para isso, em lugar de se buscar a aplicação da norma do vendedor ou do comprador, através de uma regra de conexão, ou do princípio da proximidade, ou ainda do interest analisys; no comércio internacional a solução mais eficiente foi sempre a combinação, a uniformização e a criação de uma norma comum. Deste modo, o contrato internacional é regulado por uma norma conhecida por ambas as partes. A harmonização legislativa, por tanto, desde sua origem, com o fim do Feudalismo e o início do Capitalismo, tem sido uma das diretrizes mais importantes para o comércio internacional.

O desenvolvimento do comércio internacional através, especialmente, da expansão dos meios de comunicação e a abertura dos mercados, permite que se afirme, hoje, viver-se em uma nova etapa da Globalização. Tal fenômeno, controvertido quanto à sua origem, dá-se através da 
integração econômica e social dos povos em sua esfera global, que, por sua vez, ocorre por meio da troca cultural e a expansão dos mercados nacionais (MAXEINER, 1997).

Apesar de divergências doutrinárias quanto às etapas da Globalização, é senso comum na doutrina caracterizar essa nova etapa pela crescente velocidade em que as trocas de informações são feitas e os problemas advindos desta nova realidade, como as questões envolvendo propriedade intelectual e pelo uso das novas tecnologias, como a internet. No Direito, segundo Cláudia Lima Marques, Erik Jayme afirma tratar-se de tempos pós-modernos caracterizados pela pluralidade, comunicação, velocidade, fluidez e internacionalidade das relações privadas (MARQUES, 2008).

Neste contexto, deparamo-nos com uma diversidade não apenas cultural, mas também legislativa, em que para o mesmo caso é possível aplicar mais de uma lei nacional, por vezes, uma regra internacional, ou mesmo o Direito Consuetudinário. Conclui-se, desta forma, que, cada vez mais, os diversos procedimentos de uniformização, a serem vistos mais a diante, criam, na verdade, uma variedade tão rica e não centralizada de regras de Direito do Comércio Internacional, que nos permite falar em uma uniformização desuniforme.

\section{O Direito do Comércio Internacional}

A criação do Direito Comercial Internacional dá-se pela própria uniformização das normas substanciais de direito comercial (CASTRO, 2000 e TENÓRIO, 1976). Enquanto, por outro lado, o Direito Internacional (Privado) Comercial diz respeito a regras internas relativas a conflitos mercantis com elemento internacional. Oscar Tenório destaca que tal distinção não justifica o estudo separado, uma vez que a "uniformização do direito é fruto da experiência e da observação das regras de conflitos de leis propriamente ditas dos vários países" (TENÓRIO, 1976, p. 224).

Assim sendo, Irineu Strenger define o Direito Comercial como "o complexo de normas jurídicas que regulam entre particulares relações que derivam da atividade comercial". Neste sentido, o autor entende que o Direito Comercial Internacional é parte do Direito Internacional Privado, que tem por objeto "fixar os princípios que determinam a competência das normas jurídicas dos Estados, pertencentes ao direito comercial” (STRENGER, 2005, p. 757).

No entanto, o mesmo autor defende a autonomia deste ramo, ao explicar que o Direito do Comércio Internacional, ainda em vias de consolidação, utiliza-se de meios técnicos mais amplos que o Direito interno, justamente pela natureza internacional das suas relações jurídicas. No entanto, 
a autonomia do Direito do Comércio Internacional estará sempre condicionada à efetividade da lei interna (STRENGER, 1996).

No que se refere às fontes, Maristela Basso afirma que o Direito do Comércio Internacional possui tanto fontes de direito transnacional, como de direito interno. No entanto, a autora explica que as primeiras atuam na ausência de normas nacionais, sendo objeto de grandes contestações doutrinárias. Além disso, a autora inclui no grupo de normas transnacionais a lex mercatoria e seus ramos específicos, como a lex petrolea (RIBEIRO, 2006). Em contrapartida, Irineu Strenger afirma que as normas consuetudinárias e os tratados normativos são as fontes exclusivas do Direito do Comércio Internacional, visto que, como parte do Direito Internacional, este deve manifestar-se apenas através da "vontade concorde de vários Estados" (STRENGER, 2005, p. 759).

O autor explica que há dois pressupostos fundamentais a existência do Direito do Comércio Internacional: "a diversidade das normas do direito comercial" e "a existência do comércio internacional" (STRENGER, 2005, p. 757-758).

\section{A Uniformização}

Se o fenômeno da uniformização das regras de Direito do Comércio Internacional é o reflexo da crescente integração comercial mundial ou se é, por si, o facilitador deste último, tal diagnóstico é irrelevante dado o estágio avançado em que ambos os fenômenos hoje se encontram. O que é digno de nota, sem dúvida, é a correlação entre estes dois: o comércio cresce na medida em que as normas se uniformizam e a uniformização das normas cresce na medida em que o comércio internacional se expande. Dada esta afirmativa, importa, neste momento, analisar o fenômeno da uniformização.

Como ressalta Jacob Dolinger, as diversidades fruto da cultura de cada povo são naturais e necessárias. O direito uniforme, segundo o autor, é sempre bem-vindo, quando espontâneo (DOLINGER, 2009). Oscar Tenório, seguindo a esteira de René David, cita os principais fatores de influência para as legislações como sendo os aspectos geográficos, raciais, lingüísticos, religiosos e econômicos. Continuando o autor afirma: "Sem um sentido da realidade nacional não é possível pensarmos em unificação" (TENÓRIO, 1976, p. 39).

A idéia de uma uniformização geral e universal do Direito já foi, há muito, superada. Já no século XX, a ilusão de se criar um Direito Universal se desfez. Passou-se a entender que tal ideal 
não passava de uma utopia, uma vez que o Direito Uniforme, para sua exigibilidade, depende da concessão de cada país individualmente, da aplicação uniforme de cada jurisprudência e que tal ideal era impraticável, especialmente em relação a determinados institutos do Direito Civil, que refletem a cultura e a tradição de cada povo (CASTRO, 2000).

No entanto, com o Direito Comercial, como bem ressalta Jacob Dolinger, o processo de uniformização, senão natural, faz-se, sem dúvida, necessário (DOLINGER, 2009). No mesmo sentido, Irineu Strenger entende que, no Direito Comercial, a unificação das normas de Direito Internacional Privado aparece como um anelo mais justificado (STRENGER, 2005). Por essa particularidade é que se vê a grande atividade uniformizadora no ramo do Direito Comercial. Uma vez que o comércio internacional guarda em si a consequência natural de ser multiconectado a diversos ordenamentos jurídicos distintos, é também imprescindível que suas normas venham a suprir futuros conflitos de leis.

Com este objetivo, são muitos os exemplos de normas de Direito do Comércio Internacional uniformes. Apenas a título ilustrativo, seguem as que se pode chamar de principais para o Brasil e o mundo: Convenção de Genebra para a Adoção de uma Lei Uniforme Sobre Letras de Câmbio e Notas Promissórias, de 1930; Lei Uniforme Relativa ao Cheque, de 1931; Convenção Européia sobre Resolução de Disputas Envolvendo Investimentos entre Estados e Nacionais de Outros Estados, de 1965; Convenção Interamericana Sobre Arbitragem Comercial Internacional, de 1975; Convenção de Roma, de 1980; a Convenção das Nações Unidas para a Venda Internacional de Mercadorias, de 1980; e Convenção Interamericana sobre Direito Aplicável aos Contratos Internacionais, de 1994.

\section{As Organizações Internacionais}

Não existe um domínio das relações sociais para o qual não exista uma organização encarregada de propor regras de comportamento, de aproximar as legislações nacionais e de favorecer a conclusão de tratados internacionais.

Alain Pellet, Patrick Daillier e Nguyen Quoc Dinh

Como já mencionado, são diversas as formas de uniformização do Direito Comercial. No presente trabalho, trataremos do papel das organizações internacionais, da arbitragem internacional e da lex mercatoria. 
As organizações internacionais e as organizações não-governamentais têm ganhado importante destaque no comércio internacional, uma vez que são responsáveis pela criação de normas uniformes e, muitas vezes, pela criação de uma jurisprudência internacional, posto que em seu âmbito interno estão organizados os principais tribunais arbitrais internacionais.

No momento, será estudada a estrutura administrativa dessas organizações, com destaque para o processo de criação de uma norma uniforme e analisar-se-ão, brevemente, as principais organizações internacionais que atuam no comércio internacional.

Para Alain Pellet, Patrick Daillier e Nguyen Quoc Dinh, apesar de muito teórica e restrita, a definição de Sir Gerald Fitzmaurice parece ser a mais adequada dentre aquelas apresentadas pela doutrina. Segundo este autor, as organizações internacionais são "associações de Estados, constituídas por tratado, dotada de uma constituição e de órgãos comuns, e possuindo uma personalidade jurídica distinta da dos Estados membros" (PELLET, at. al., 2003, p. 592). Os autores acima citados lembram ainda que a Convenção de Viena sobre Direito dos Tratados, de 1969, em seu art. $2^{\circ}, \S 1^{\circ}$, “i” não traz uma definição do que venha a ser uma organização internacional, destacando apenas que estas são entendidas como "organizações intergovernamentais", ressaltando a grande distinção entre estas e as ONGs. (PELLET, at. al., 2003)

Celso Mello traz em seu Manual a definição de Angelo Piero Sereni que tem em si a vantagem de detalhar todas as características das organizações (MELLO, 1994, p. 507):

[O]rganização internacional é uma associação voluntária de sujeitos de direito internacional, constituída por ato internacional e disciplinada nas relações entre as partes por normas de direito internacional, que se realiza em um ente de aspecto estável, que possui um ordenamento jurídico interno próprio e é dotado de órgãos e institutos próprios, por meio dos quais realiza as finalidades comuns de seus membros mediante funções particulares e o exercício de poderes que lhe foram conferidos.

A partir da idéia de que a organização constitui-se em um "ente de aspecto estável" é que Celso Mello entende derivar a personalidade jurídica da organização (MELLO, 1994). Sobre o assunto, Ian Brownlie afirma que ser sujeito de Direito Internacional é possuir direitos e deveres internacionais e ter capacidade para defender seus direitos através de uma reclamação internacional. Deste modo, o autor observa que a questão da personalidade envolve a "capacidade para apresentar reclamações sobre violações do Direito Internacional, capacidade para celebrar tratados e acordos válidos no plano internacional, e gozo de privilégios e imunidades concedidos por jurisdições nacionais" (BRONWLIE, 1990, p. 71). Assim sendo, o autor conclui que os Estados e as 
organizações são os únicos tipos normais de sujeito no cenário internacional, apesar de reconhecer tipos congêneres (BRONWLIE, 1990). Entende-se que a personalidade jurídica da organização internacional é, em regra, derivada da vontade do Estado - principal agente internacional, cujos direitos e deveres são amplos devido ao princípio da soberania que apenas a ele é conferido. Como foi visto, este é um dos elementos de sua própria definição e, por isso mesmo, diz-se que toda organização devidamente constituída tem personalidade jurídica (PELLET, at. al., 2003).

Outra observação a cerca da personalidade jurídica da organização internacional é, devido ao fato de esta ser derivada e, consequentemente, variável, pois depende do que os Estados acordam ser de competência daquela organização. No entanto, há um "núcleo duro" da personalidade que é chamado por Alain Pellet, Patrick Daillier e Nguyen Quoc Dinh de funcionalidade. Esta funcionalidade depende justamente das atribuições de cada organização (PELLET, at. al., 2003). Por esta razão, a doutrina explica que a verificação da personalidade jurídica de uma organização é feita através do critério funcional. Com base nisso, Ian Brownlie estabeleceu três critérios para aferição da personalidade jurídica (BRONWLIE, 1990):

1. uma associação permanente de Estados, que prossegue fins lícitos, dotada de órgãos próprios;

2. uma distinção, em termos de poderes e fins jurídicos, entre a organização e os seus Estados membros;

3. a existência de poderes jurídicos que possam ser exercidos no plano internacional, e não unicamente no âmbito dos sistemas nacionais de um ou mais Estados.

A doutrina classifica a personalidade jurídica da organização internacional entre interna e internacional ou externa. A primeira diz respeito à capacidade de a organização, dentro do território de um Estado soberano, exercer atividades necessárias para a sua manutenção, como contratação de funcionários e compra de imóveis. Já a personalidade internacional, segundo João Mota de Campos, é o "conjunto de direitos, obrigações e prerrogativas que se manifestam em relação aos outros sujeitos de Direito Internacional" (CAMPOS, 1999, p. 156), daí, pode-se afirmar, por exemplo, a capacidade de uma organização demandar contra um Estado.

Concluindo, pode-se dizer que as organizações internacionais são aquelas com objetivos definidos pelos Estados. No entanto, guardam com relação a estes certa independência no que se refere a sua capacidade de decisão. Outra característica importante é a sua atuação permanente, distinguindo-se, assim, das conferências internacionais. 
A partir disso, importa analisar, então, as competências das organizações internacionais. Alain Pellet, Patrick Daillier e Nguyen Quoc Dinh apontam para a existência de três categorias de competência: a competência operacional, a normativa e a jurisdicional ou quase jurisdicional. A primeira diz respeito à competência da organização de criar normas para sua própria gestão, âmbito no qual se destacam as normas orçamentárias (PELLET, at. al., 2003).

Sobre a competência normativa, a doutrina costuma dividir as normas que regulam a ordem jurídica das organizações internacionais em Direito Originário, em referência às normas que criam a organização, como o seu ato constitutivo e o Direito Internacional Comum, e em Direito Derivado, relativo às normas criadas pela própria organização e às quais, naturalmente, está obrigada (CAMPOS, 1999). É deste Direito Derivado que surge, propriamente dito, o Direito Uniforme Comercial Internacional. Segundo Rezek, tal competência tem tanta importância que a existência de uma organização internacional sem poderes para celebrar tratados é questionável (REZEK, 1991). Neste sentido, o autor destaca a definição de organização internacional defendida por René-Jean Dupuy em que se destaca esta função normativa: “[são organizações internacionais] aquelas que, em virtude de seu estatuto jurídico, têm capacidade de concluir acordos internacionais no exercício de suas funções e para a realização de seu objetivo" (REZEK, 1991, p. 251). Por outro lado, o autor, assim como Celso Mello, ressalta que a personalidade jurídica não induz automaticamente que haja capacidade para celebrar tratado: é preciso que o ato criador da organização assim determine. (MELLO, 1994) Além disso, a Convenção de Viena sobre Direito dos Tratados, de 1986, estabelece em seu art. $6^{\circ}$ que: "a capacidade de uma organização internacional para celebrar tratados é regulada pelas normas da organização."

Este Direito Derivado surge, então, do processo decisório das organizações internacionais que enseja a criação de normas unilaterais. Rezek afirma que toda organização deve ter, ao menos, dois órgãos: uma assembléia geral, em que os Estados-membros se reúnem periodicamente e votem em igualdade de condições; e um conselho permanente, que funciona ininterruptamente e exerce função executiva, podendo ser composto por representantes de todos os Estados-membros ou apenas de alguns (REZEK, 1991). Alain Pellet, Patrick Daillier e Nguyen Quoc Dinh mencionam ainda a importância dos órgãos jurisdicionais cujas atividades são totalmente independentes dos órgãos intergovernamentais, bem como as dos órgãos consultivos, responsáveis pelos trabalhos preparatórios, sem iniciativa para definir o conteúdo de seus trabalhos, funcionando como um órgão 
auxiliar ao secretariado. O secretariado ou comissão é outro órgão cuja importância administrativa é imprescindível para a gestão da organização internacional.

No que se refere ao processo decisório, Rezek reconhece que, nas organizações internacionais, o princípio majoritário não é praticado da mesma forma como no Direito Interno, de modo que a submissão da minoria não é comum no âmbito internacional - com exceção da União Européia, como será visto mais a diante. Por outro lado, Alain Pellet, Patrick Daillier e Nguyen Quoc Dinh reconhecem que a adoção do sistema majoritário é comumente adotada de modo análogo aos sistemas internos dos Estados-membros, de forma a "democratizar" a vida política internacional. Ainda segundo este autor, como este sistema desfavorece as grandes potências, muitas vezes, adotase o sistema de ponderação dos votos, como no caso do Fundo Monetário Internacional e o Banco Mundial, nos quais o valor de cada voto corresponde proporcionalmente às contribuições em capital de cada país, assemelhando-se ao regime interno de uma sociedade comercial. Não obstante, os órgãos da organização podem ainda optar pelo sistema do consenso. Este sistema é adotado quando uma decisão tomada por maioria deve ser adotada por todos os Estados, inclusive aqueles que compuseram minoria. Nas palavras de Alain Pellet, Patrick Daillier e Nguyen Quoc Dinh, "[este sistema] apresenta o inconveniente de traduzir em geral um compromisso sobre um desacordo" (2003, p. 641). Contudo, através do consenso, tem-se a grande vantagem de se evitar que a decisão aprovada torne-se letra morta, uma vez que aqueles países que foram contra a sua aprovação poderiam terminar por não a incorporar ao seu ordenamento jurídico ou não a executar, dependendo do regime adotado por aquela organização.

Entendido o conceito, as competência e funções da organização internacional, torna-se fácil compreender como estas instituições são importantes para a uniformização do Direito do Comércio Internacional. Como visto, a principal competência das organizações internacionais é a elaboração de tratados através de seus órgãos descritos acima. Antes de verificarmos como esta tarefa é feita, importa destacar a observação feita por Claire R. Kelly sobre o fato de que o papel político das organizações internacionais pode ser "puro" como um Estado que pressiona para que uma norma internacional seja criada, de modo a pressionar uma harmonização legal. Por outro lado, esta tarefa pode refletir uma preferência política e, assim, a organização deve escolher: "What situations need norms? Which or whose norms? How should norms be implemented?". Segundo a autora, este é o modo pelo qual as decisões da organização adquirem legitimidade o que é de extrema importância para a efetivação de seus trabalhos (KELLY, 2009, p. 21). 
No caso das organizações internacionais, diferentemente dos Estados, o poder de concluir um tratado não advém de sua soberania, posto que este não é um de seus atributos, mas de suas finalidades e as disposições específicas de seu tratado constitutivo. Por esta razão, o processo de adoção de um tratado por uma organização varia conforme a instituição. Contudo, José Cretella Neto resume o que seria o procedimento comum: o secretariado deposita o tratado e convoca os membros da organização para reuniões - debates que podem vir a ser feitos em assembléias gerais ou extraordinárias - e é responsável por supervisionar a implementação das convenções.

No entanto, a criação de tratados não é a única forma pela qual uma organização ajuda no processo de uniformização. Estas funcionam também como fóruns da prática dos Estados quando estes se manifestam, através de seus representantes, declarando quais são suas regras internas e o costume comercial de seu país. Além disso, a organização internacional tem grande importância para a formação de um Direito Consuetudinário, através da aprovação de resoluções que, muitas vezes, não são vinculativas, mas apenas declarativas. É importante destacar que a interpretação das normas de uma organização é feita por seus órgãos internos, de forma a evitar desacordos entre Estados-membros. Os atos interpretativos não são vinculativos, mas não podem ser ignorados pelos países membros. Outras atividades podem ainda ser citadas, como (i) a atuação de peritos jurídicos que trabalham na codificação e o desenvolvimento progressivo do Direito; (ii) as decisões judiciais que ajudam na uniformização da interpretação das normas de Direito Internacional; (iii) as declarações oficiais de aplicação sobre determinado assunto; etc (BRONWLIE, 1990).

Importa destacar que a atividade das organizações internacionais no sentido de unificar o Direito Comercial não está isenta de críticas. Em primeiro lugar, observa-se uma variedade de organizações que, se não têm as mesmas finalidades, posto que isto não seria possível devido ao princípio da especialidade, muitas vezes, seus objetos se confundem, como é o caso da Organização Mundial do Comércio e a Organização Mundial da Propriedade Intelectual, da ONU; além do conflito entre a jurisdição da OMC e outros, como o do Mercosul. Além disso, é importante deixar claro que o tratado convencionado no âmbito de uma organização internacional, em regra, não tem aplicação para os Estados não-membros, mantendo-se, assim, a diversificação legislativa.

\section{A Arbitragem Internacional}

"Procedural lex mercatoria" should therefore continue also to be the primary generator of the "substantive lex mercatoria"; and both can allow 
us to better understand how law evolves, especially in our increasingly globalised world.

Luke Nottage

As organizações internacionais, como visto, além da competência normativa, têm também uma competência jurisdicional ou quase jurisdicional. É através da atuação de cortes arbitrais internacionais, que funcionam no âmbito das organizações internacionais, que a arbitragem internacional tornou-se uma das fontes mais importantes do Direito Consuetudinário Comercial Internacional, sendo, para alguns autores, um dos elementos da própria lex mercatoria (STRENGER, 1996).

Segundo José Maria Garcez, para René David, a arbitragem é:

a técnica que visa a solucionar questões de interesse entre duas ou várias pessoas, por uma ou mais pessoas - o árbitro ou os árbitros - os quais têm poderes resultantes de convenções privadas e decidem, com base nessa convenção, sem estar investidos dessa missão pelo Estado (1999, p. 163164).

A arbitragem será internacional segundo, basicamente, os mesmos critérios de diferenciação entre um contrato internacional e nacional, ou seja, quando está conectada a mais de um ordenamento jurídico, seja por aspectos subjetivos - nacionalidade das partes -, seja por aspectos objetivos, como o local de celebração ou execução do contrato. Além disso, a arbitragem internacional tem ainda o particular de necessitar de homologação judicial para a sua execução.

Jacob Dolinger e Carmen Tiburcio lembram a importância da distinção entre uma arbitragem nacional e internacional, posto que a nacionalidade da mesma (DOLINGER; TIBURCIO, 2003, p. 91):

(i) "determina a lei que regula a arbitragem, que será, em princípio, a lei dessa nacionalidade";

(ii) "determina o tribunal estatal que poderá vir a ter jurisdição sobre o processo arbitral, caso uma intervenção se faça necessária; e"

(iii) "identifica o procedimento a ser seguido para a execução do laudo arbitral, pois normalmente um laudo proferido internamente é mais facilmente executável do que um proferido alhures." 
No Brasil, o STF sempre homologou laudo arbitral proferido no exterior, o que permitia à doutrina concluir que o critério adotado era o geográfico, o que, posteriormente, passou a ser expresso na Lei n ${ }^{\circ}$ 9.307, de 23 de setembro de 1996, a Lei de Arbitragem (art. 34) (DOLINGER; TIBURCIO, 2003).

A Lei-Modelo da Uncitral sobre Arbitragem internacional traz a seguinte definição mais ampla e coerente com a realidade comercial:

An arbitration is international if:

(a) the parties to an arbitration agreement have, at the time of the conclusion of that agreement, their places of business in different States; or

(b) one of the following places is situated outside the State in which the parties have their places of business:

(i) the place of arbitration if determined in, or pursuant to, the arbitration agreement;

(ii) any place where a substantial part of the obligations of the commercial relationship is to be performed or the place with which the subject-matter of the dispute is most closely connected; or

(c) the parties have expressly agreed that the subject matter of the arbitration agreement relates to more than one country.

Como tal, a arbitragem, atualmente, é o meio de solução de controvérsias fora do Poder Judiciário mais utilizado. Jacob Dolinger e Carmen Tiburcio concluem que, "[p]rova disso é a existência de inúmeras e respeitadas instituições que atuam no sentido de efetivar a sua realização" (DOLINGER; TIBURCIO, 2003, p. 49). Verificar-se-á que cada vez mais a arbitragem internacional tem se usado da eqüidade, dos princípios gerais de direito, das práticas do comércio internacional e de tratados internacionais.

Assim sendo, conclui-se que a arbitragem é o meio pelo qual todas as regras de comércio internacional - traduzidas nas convenções internacionais ou adotadas pelos agentes do comércio através dos costumes e princípios gerais - encontram uma sistematização e uniformização interpretativa, criando, desta forma, uma jurisprudência internacional de forte impacto para os agentes do comércio internacional. A uniformização do Direito do Comércio Internacional através da arbitragem internacional, portanto, dá-se de três modos: pela uniformização das regras procedimentais, facilitando o reconhecimento dos laudos estrangeiros; pela interpretação das regras internacionais; e pelo uso de precedentes.

Por outro lado, Gary Born destaca que a arbitragem internacional, apesar de ser consensualmente um meio de solução de controvérsias, só encontra sua eficácia devido ao complexo 
ordenamento legal nacional e internacional, posto que é devido a obrigatoriedade trazida por essas normas que os Estados reconhecem os laudos arbitrais (BORN, 2001).

No que concerne às vantagens da arbitragem, segundo Jose Maria Garcez, para William F. Fox Jr., busca-se a arbitragem a fim de se evitar os longos processos judiciais, posto que o Poder Judiciário está sempre às voltas com infinitos recursos e lentidão causada pela grande quantidade de demandas judiciais (GARCEZ, 1999). Além disso, a arbitragem oferece um tratamento confidencial, protegendo os segredos comerciais das partes em litígio. Jacob Dolinger e Carmen Tiburcio destacam, ainda, o fato de os árbitros serem escolhidos tendo em vista seu conhecimento na área comercial de dado conflito, tornando-se aptos a elaborar um laudo de melhor qualidade comparativamente a um juiz (DOLINGER; TIBURCIO, 2003). A doutrina cita ainda a vantagem de escolha do local da arbitragem como forma de buscar um país neutro, evitando-se, assim, sentenças enviesadas (GARCEZ, 1999). Muito se fala também sobre buscar-se um procedimento menos dispendioso. No que se refere a esta última vantagem, Luke Nottage destaca que esta é uma vantagem relativa, visto que, em alguns casos o processo arbitral pode ser tão dispendioso quanto ao processo judicial (NOTTAGE, 2006). Destaca-se, ainda, a possibilidade de as partes escolherem a lei a ser aplicável, inclusive optando pela utilização do princípio da equidade. Por isso tudo, Gary Born afirma que a arbitragem comercial internacional traduz maior segurança às partes (BORN, 2001).

A seguir, faz-se uma breve análise das diversas organizações internacionais e cortes internacionais arbitrais cujos trabalhos se relacionam com o comércio internacional, sem, contudo, pretender-se esgotar os exemplos:

\section{UNCITRAL}

A United Nations Commission on International Trade Law - UNCITRAL - é o órgão das Nações Unidas responsável pelo desenvolvimento de normas internacionais sobre comércio. Criado em 1967 com 29 membros, hoje é composto por cerca de 60 Estados-membros. Seu objetivo é a preparação de instrumentos legais sobre comércio internacional, dentre os temas destacam-se: falência, transporte, venda, seguros, arbitragem comercial, pagamento internacional, propriedade intelectual, legalização de documentos, etc (UNCITRAL, 2009).

Seu procedimento decisório está submetido às regras gerais da Assembléia Geral da ONU e envolve: (i) a Comissão, (ii) Grupos de Trabalho (composto, inclusive, por não membros) e (iii) o 
Secretariado. Importante destacar que a Comissão e o Grupo de Trabalho atuam por consenso. No entanto, o sentido de consenso não é claro. A Comissão fala em uma "grande cooperação" entre países com realidades econômicas, legais e socias diferentes (KELLY, 2009). Em suas observações,

a França critica este método, tendo em vista o aumento de membros na Comissão (UNCITRAL, 2007).

Dentre seus vários trabalhos já realizados, o grande destaque, sem dúvida, é a Convenção de Viena das Nações Unidas sobre Compra e Venda Internacional de Mercadorias (CISG, em inglês). Aprovada em 11 de abril de 1980, a Convenção entrou em vigor apenas em 1988, para os onze primeiros países que depositaram, junto ao Secretariado, seus instrumentos de adoção (Argentina, China, Egito, Estados Unidos, França, Hungria, Itália, Iugoslávia, Lesoto, Síria e Zâmbia).

Com o objetivo de uniformizar e formalizar o procedimento arbitral internacional, a Comissão elaborou a Convenção sobre o Reconhecimento e Execução de Sentenças Arbitrais Estrangeiras, conhecida como a Convenção de Nova Iorque, de 1958. Hoje, a Convenção conta com 144 Estados signatários. Os quatro países-membros do Mercosul adotaram a convenção sob reserva de reciprocidade. Deste modo, a Convenção tem largo escopo de aplicação e é uma referência para o Direito do Comércio Internacional.

Em 1985, é criada a chamada Lei Modelo da UNCITRAL sobre Arbitragem Comercial Internacional. Segundo o Pieter Sanders, o impacto da Convenção fora tal que nenhum Estado que veio a modernizar sua lei de arbitragem, o fez sem considerar suas disposições (GARCEZ, 1999). Em 2006, a Convenção foi revista, tendo sido acrescido um capítulo sobre Medidas Cautelares.

\section{OMC}

A Organização Mundial do Comércio é sem dúvida a organização de maior importância para a uniformização do Direito do Comércio Internacional. Criada pelos países membros do GATT (General Agreement on Tariffs and Trade) na Rodada Uruguai, em 1994, hoje se encontra com 153 membros efetivos e 30 países observadores (OMC, 2010).

A OMC tem como fim regular o comércio internacional através de limites contra a intervenção Estatal em sua economia nacional de modo a não prejudicar em efeito cascata a economia mundial. Um dos mecanismos de aplicação de suas regras é através do seu sistema de arbitragem internacional através do qual um país pode acionar outro país-membro que julgar estar 
intervindo deslealmente na economia ou de modo a desrespeitar as regras desta organização, bem como os usos e costumes do comércio internacional.

Pode-se dizer, portanto, que a OMC tem duas funções no que concerne a uniformização do Direito do Comércio Internacional: a criação de leis uniformes, servindo como fórum de debate para os países-membros e como órgão de solução de controvérsias. Sobre este último aspecto, merece destaque sua abrangência. $\mathrm{O}$ alcance do sistema de solução de controvérsias da OMC, apesar de sua repercussão no comércio internacional como um todo e de seu efeito prático sobre os agentes econômicos privados de todo o mundo, não pode ser acionado por países que não sejam membros efetivos da Organização. Os países observadores, organizações internacionais, regionais ou locais não têm legitimidade para tanto. Deste modo, através de suas decisões, a OMC flexibilizou a possibilidade de terceiros (empresas e indivíduos privados) participarem das controvérsias como amicus curiae, apesar de este ainda ser um tema controvertido entre os membros da organização (OMC, 1998). São dois os órgãos envolvidos no processo de solução de controvérsia: o Órgão de Solução de Controvérsia (DSU), responsável por garantir o respeito às normas de solução de controvérsias da OMC, que pode vir a solicitar, por sua vez, o estabelecimento do Grupo Especial, também chamado de Panel, que tem como objetivo: "a busca por informações e conselho técnico de qualquer indivíduo ou organização que considere adequada" (art. 13 do Understanding on rules and procedures governing the settlement of disputes (Anexo 2 do WTO Agreement).

Por fim, vale destacar o método de votação da OMC. Após ter sido criada na Rodada Uruguai, a principal mudança, sem dúvida, foi a eliminação do voto de consenso para a formação de painéis era necessário o consentimento de todos os membros do acordo para a adoção de relatórios do Painel, inclusive do Estado acusado (FELIX, 2002). Este era o chamado sistema de consenso positivo. A partir de 1995, passou a ser adotado o sistema de consenso negativo. Este novo sistema consiste em proibir o bloqueio do relatório do painel, em outras palavras, "um relatório só poderá ser rejeitado se houver consenso quanto à rejeição (artigo 16.4 para relatórios dos painéis e artigo 17.14 para relatórios do Órgão de Apelação - AO, ambos dispositivos do ESC)" (LUPI, 2001). Esta mudança teve efeitos diretos sobre a efetividade das soluções advindas do âmbito da OMC, posto que, deste modo, uma vez feito o relatório pelo Painel, este dificilmente será vetado e terá sua aplicação determinada por prazo estabelecido caso a caso. Outro efeito importante verifica-se quando analisamos o impacto das decisões no âmbito da OMC que, apesar de relativas a um caso particular, repercute por todo o comércio internacional. 
Uma observação importante diz respeito à possibilidade de atos privados serem questionados no âmbito da OMC. O entendimento dominante é que isso não é possível uma vez que as regras da OMC estabelecem compromissos governamentais que, por esta razão, não poderiam ser infringidos por uma empresa privada, por exemplo. No entanto, reconhece-se que há possibilidade de atos privados estarem intrinsecamente ligados a atos do governo, como incentivos, que poderiam vir a ser objeto de controvérsia, tendo somente o Estado-membro como sujeito passivo (OMC, 2010).

Alguns exemplos de convenções criadas no âmbito da OMC são: Acordo Sobre a Implementação do Artigo VI do Acordo GATT 1994, sobre medidas anti-dumping; Acordo sobre Regras de Origem, que entrou em vigor em 1995; e o Acordo sobre Aspectos dos Direitos de Propriedade Intelectual Relacionados ao Comércio, de 1994.

\section{OEA}

Apesar de lhe faltar uma corte arbitral específica para conflitos comerciais, a OEA, composta atualmente por 35 Estados-membros, tem importantes convenções a respeito do tema. A Convenção Interamericana do Panamá sobre Arbitragem Comercial Internacional, de 1975, é hoje ratificada por 19 países (dentre os quais, os quatro integrantes do Mercosul e os Estado Unidos da América que assinaram com reserva de reciprocidade). A Convenção foi criada para facilitar a validade de laudos arbitrais dos países-membros da Organização em seus territórios. Ela ainda prevê a utilização das normas procedimentais da Comissão Interamericana de Arbitragem Comercial, em caso de as partes não chegarem a um acordo sobre as regras aplicáveis (art. $2^{\circ}$ ). Segundo Carmen Tiburcio, a Convenção tem âmbito de aplicação bastante amplo, posto que, dentre outros assuntos, ela regula a vigência extraterritorial de laudos arbitrais, a validade das cláusulas compromissórias e do compromisso, etc. (ARAUJO; CASELLA, 1998). Conclui Lauro Gama que esta é, portanto, "um dos mais importantes e profícuos frutos da Primeira Conferência Especializada Internamericana sobre Direito Internacional Privado (CIDIP-I)", tendo em vista, inclusive, que seu âmbito de aplicação não se restringe aos Estados americanos (ARAUJO; CASELLA, 1998, p. 373).

\section{União Européia}

A União Européia (UE) é um organismo internacional cujos Estados-membros já atingiram tal grau de integração que, hoje, representa o único bloco econômico na fase de mercado comum no 
mundo. A União Européia tem importante função no processo de uniformização do Direito do Comércio Internacional, uma vez que a criação de normas uniformes entre os Estados-membros é própria do seu objetivo de facilitar as trocas comerciais entre os países. A este Direito nascido no âmbito da UE dá-se o nome de Direito Comunitário (MELLO, 1996).

Celso Melo afirma que o Direito Comunitário é um ramo do Direito Internacional Público, com aspectos sui generis, dentre os quais a supranacionalidade (MELLO, 1996). Algumas das principais características do Direito Comunitário são: o efeito impositivo, ou seja, a obrigatoriedade de seu cumprimento com previsão de sanções, em caso de o Estado-membro da Comunidade não o respeitar; primazia com relação ao Direito Interno dos Estados; o efeito direto, ou seja, o Direito Comunitário independe de um procedimento de recepção para ter eficácia no âmbito interno dos Estados, com algumas exceções; e uniformidade de interpretação e aplicação (FRANCA FILHO, 2002).

Com relação ao processo de criação das normas, os órgãos da UE responsáveis pelas mesmas são: o Parlamento Europeu, o Conselho da União Européia, a Comissão e os Tribunais de Justiça e de Contas. O Parlamento Europeu é hoje composto por 736 parlamentares eleitos diretamente pelos cidadãos dos Estados-membros da UE (EU, 2010). Importante observar que os parlamentares europeus não estão vinculados aos interesses de seu país de nacionalidade, mas sim a posição política adotada por seu partido. É, portanto, o principal órgão responsável pela criação de normas, junto com o Conselho da União Européia, em um processo chamado de co-decisão (Previsto no artigo $251 .^{\circ}$ do Tratado CE e instituído pelo Tratado de Maastricht.). Este processo dá-se sempre quando uma norma for adotada por maioria pelo Conselho da União Européia, posto que deverá, então, seguir para votação do Parlamento. No entanto, às matérias relativas à União Econômica e Monetária ainda se aplica o processo de cooperação (que tem perdido espaço para o processo de codecisão). Segundo Casella, esta é uma forma de o Parlamento melhorar a legislação proposta (CASELLA, 2002) e segue o seguinte rito:

O procedimento de cooperação inicia-se sempre por uma proposta da Comissão, que é transmitida ao Conselho e ao Parlamento Europeu. (...) o Parlamento emite um parecer sobre a proposta da Comissão. O Conselho, deliberando por maioria qualificada, estabelece, então, uma posição comum (...).

O Parlamento examina a referida posição (...). No caso de rejeitar a proposta, o Conselho só pode deliberar em segunda leitura por unanimidade. 
A Comissão reexamina então, no prazo de um mês, a proposta que constituiu a base para o Conselho estabelecer a respectiva posição comum e transmite a sua proposta ao Conselho (...).

No prazo de três meses, o Conselho pode aprovar a proposta reexaminada por maioria qualificada, alterar a proposta reexaminada por unanimidade ou aprovar as alterações que não foram consideradas pela Comissão, também por unanimidade." (UE, 2010)

No que se refere à criação de normas uniformes, essas já atingiram um grande número,

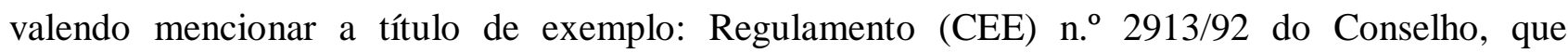
estabelece o Código Aduaneiro Comunitário; e o Regulamento (CE) n. ${ }^{\circ}$ 1184/2006 do Conselho, de 2006, relativo à aplicação de determinadas regras de concorrência à produção e ao comércio de produtos agrícolas.

Além dessas, encontram-se algumas normas uniformes precisamente sobre arbitragem, como a Convenção Européia sobre Arbitragem Comercial Internacional, firmada em Genebra, em 1961. Criada no âmbito da Comissão Econômica para a Europa, esta Convenção atualmente é aplicada por todos os países da Europa, com exceção de Portugal e Inglaterra.

No entanto, quanto ao seu papel na uniformização do Direito do Comércio Internacional através da função jurisdicional, a União Européia destaca-se mesmo pelo trabalho do Tribunal de Justiça das Comunidades Européias e o Tribunal de Primeira instância. Para a construção de um mercado comum, a UE necessita de um mecanismo para tornar eficazes suas normas. Casella explica que, para isso, faz-se necessária a adoção de parâmetros jurisdicionais em escala comunitária, de modo que, Ulrich Everling chega a falar em um "direito jurisprudencial da Comunidade Européia" (CASELLA, 1994).

A doutrina, de modo geral, vê de modo bastante positivo a atuação dos Tribunais europeus que até hoje, desde sua criação em 1952, já proferiram mais de 15.000 acórdãos (UE, 2010).

Através de seu trabalho, o Tribunal de Justiça garante a interpretação e aplicação uniforme do Direito Comunitário. Ele é composto por 15 juízes e assistido por 9 advogados-gerais escolhidos entre personalidades que garantam independência com relação ao Estado de sua nacionalidade e atendam nesses territórios os requisitos necessários para exercerem a profissão (LOBO, 2001).

O trabalho dos advogados se restringe à manifestação através das Conclusões Gerais, de modo a serem imparciais e independentes. A esse Tribunal competem ações envolvendo dois ou mais Estados-membros da UE, de forma que não permite a solução de conflitos diretos entre uma empresa e um Estado-membro que, por ventura, desobedeça uma norma comunitárias, mas funciona 
como um órgão supranacional capaz de impor a interpretação harmônica das normas comunitárias para os Estados diretamente. Deste modo, trabalha com demandas constitucionais (envolvendo o Tratado de Maastricht, firmado em 1992, criador da, então, Comunidade Européia); administrativas (referentes a legalidade dos atos adotados pelas demais Instituições da UE); cíveis (em caso de responsabilidade extracontratual); trabalhistas (para casos envolvendo exclusivamente funcionários da organização). Além disso, pode o Tribunal trabalhar com jurisdição voluntária ou contenciosa. No primeiro caso, quando há procedimento de reenvio prejudicial a pedido dos órgãos jurisdicionais nacionais e, no caso de jurisdição contenciosa, a doutrina costuma dividir em quatro os tipos de contenciosos:

(i) contencioso de legalidade: dentro do qual entram as ações de anulação, por omissão, exceção de ilegalidade, de indenização por responsabilidade extracontratual da Comunidade, e;

(ii) contencioso pleno: comumente relativo às diretrizes, este procedimento se inicia por iniciativa da Comissão, quando esta verifica que um Estado não está cumprindo alguma determinação legal e, por isso, emite um parecer com prazo a ser cumprido. Se, ainda sim, o Estado não o cumprir, a Comissão pode, então, recorrer ao Tribunal (LOBO, 2001).

Além disso, pode o Tribunal funcionar como órgão revisor dos acórdãos do Tribunal de Primeira Instância. Será também competente sempre que assim determinar a cláusula compromissória advinda de conflitos entre Estados-membros seja no âmbito do Direito Público, seja no âmbito do Direito Privado. Por fim, o Tribunal tem competência consultiva, pela qual cabe ao Tribunal opinar, quando assim requerer o Conselho, a Comissão ou qualquer Estado-membro, sobre um projeto (LOBO, 2001).

Estão, inclusive, previstas medidas provisórias, mas a execução de suas decisões depende das normas internas de cada Estado. Importa, por fim destacar que suas deliberações são sempre sigilosas (LOBO, 2001).

Já o Tribunal de Primeira Instância, criado apenas em 1988, é composto por 15 juízes, seguindo a mesma regra do Tribunal de Justiça quanto à nomeação e à renovação dos cargos. Quanto a sua competência, destaca-se um grande avanço realizado no âmbito da UE, ao se permitir a participação de pessoas físicas ou jurídicas em demandas perante um tribunal internacional. O Tribunal de Primeira Instância tem competência para julgar qualquer ação de omissão, anulação ou responsabilidade civil proposta contra a Comunidade, além de ações envolvendo Direito da 
Concorrência e litígios entre a Comunidade e seus funcionários. Tudo isso tendo por trás a principal de suas funções que é o controle e a interpretação das normas comunitárias (LOBO, 2001).

Ana Paula Tostes chega a afirmar que a vigência de todo o Direito Comunitário deve-se ao trabalho do Tribunal de Justiça, uma vez que apenas com as medidas coercitivas impostas por ele é que a normativa supranacional consolida-se, junto com as bases políticas da soberania da EU (TOSTES, 2004). A autora destaca que a penetração do Direito Comunitário no cotidiano da vida européia deveu-se ao trabalho de decisão em decisão da Corte e à conquista, pouco a pouco, de sua legitimidade (TOSTES, 2004).

\section{Mercosul}

O Mercosul (Mercado Comum do Sul) é um bloco econômico composto pelo Brasil, Argentina, Paraguai e Uruguaia, constituído pelo Tratado de Assunção, de 1991, e redefinido pelo Protocolo de Ouro Preto (POP), em 1994 (AMBOS; PEREIRA, 2000). Desta forma, o bloco nasceu com uma estrutura provisória e, apenas com o POP adquirir personalidade jurídica. Apesar de ainda não ter atingido as características de um mercado comum, mas ser considerado apenas uma zona de livre comércio, o bloco representa um grande avanço para a integração econômica da América do Sul. Segundo Ana Cristina Pereira, o Mercosul foi criado nos anos 1990, período que se caracterizou por um boom de criação de instituições similares, tendo em vista a crescente interdependência entre os Estados (AMBOS; PEREIRA, 2000).

Como visto, as organizações internacionais têm relevante papel na elaboração de normas internacionais e com o Mercosul isso não é diferente. Em seu âmbito, surge o supra mencionado Direito Derivado, também chamado de Direito da Integração. A doutrina, neste aspecto, discute com especial interesse a obrigação de incorporação das normas emanadas pelo Mercosul e sua relação com as normas internas de cada país. Resumidamente, o que se pode afirmar é que, conforme disposto nos artigos 38 e 40 do Tratado de Conceição e os artigos 41 e 42 do POP, há sim o dever de incorporar aos ordenamentos jurídicos internos as normas do Mercosul dentro de um prazo previsto. No entanto, apenas com a incorporação nos quatro países membros é que a norma torna-se obrigatória. Visto se tratar de um bloco com uma estrutura orgânica intergovernamental, as normas do Mercosul são aprovadas por consenso de seus membros. Pode-se, então, concluir que se, por um lado, há blocos de natureza supranacional, como a União Européia, cuja criação de normas tem caráter majoritário e a incorporação ocorre de maneira imediata, por outro lado, nos blocos de 
natureza intergovernamental, como o caso do Mercosul, não há compartilhamento da soberania nacional, mas a aplicação da regra da unanimidade (BAPTISTA, 1998) e a conseqüente necessidade de adoção de medidas no plano interno com o objetivo de incorporar as decisões do bloco.

Os principais órgãos responsáveis pela elaboração de normas no âmbito do Mercosul são o Conselho do Mercado Comum e o Grupo Mercado Comum, assistidos pela Comissão de Comércio. Segundo Luiz Olavo Baptista, os dois primeiros órgãos funcionam como foro de negociação (POP, art. 3 a 9), além disso, o Conselho tem uma função político-diplomática, atuando na conduta política e representação do Mercosul (BAPTISTA, 1998). Por seu turno, a Comissão de Comércio, subordinada ao Grupo, tem função mais ampla, onde se inclui o poder de propor normas e/ou a modificação das mesmas para seu órgão superior (BAPTISTA, 1998). Ademais, há outros órgãos também atuantes na elaboração de normas tais como: a Comissão Parlamentar Conjunta e o Foro Consultivo Econômico Social (MELLO, 1996).

O Mercosul auxilia na uniformização do Direito do Comércio Internacional não apenas através da elaboração de normas internacionais, mas também através de seu sistema de solução de controvérsia. Regulado pelo Protocolo de Brasília, de 1991 e revisado pelo Protocolo de Olivos, em 2002, o sistema de solução de controvérsias do Mercosul é competente para julgar qualquer divergência referente às decisões do Conselho do Mercado Comum e as resoluções do Grupo Mercado Comum, bem como delimitar a interpretação que deve ser feita destes instrumentos.

O Tratado de Assunção, ao constituir o Mercosul, previu a criação de um mecanismo de solução de controvérsias a ser criado no prazo de 180 dias. Deste modo, foi elaborado o Protocolo de Brasília, em 1991, com regras provisórias que, posteriormente, ganharam melhores contornos com o Protocolo de Olivos, de 2002, que, no entanto, manteve a estrutura básica do sistema. Este Protocolo garantiu maior segurança jurídica no âmbito do Mercosul e a correta aplicação de suas normas (NOHMI, 2005). Aumentando, assim, a legalidade do bloco (NOHMI, 2005). Apesar disso, Barral afirma que a flexibilidade do sistema anterior tem a vantagem de propiciar alternativas menos formais frente a uma situação de crise (NOHMI, 2005).

O procedimento atual prevê três etapas para a solução de um conflito advindo da aplicação ou interpretação dos atos normativos do Mercosul: (i) negociações diretas; (ii) considerações do Grupo Mercado Comum; e (iii) procedimento arbitral.

O Protocolo de Olivos prevê a participação exclusiva das partes envolvidas. O procedimento deve, portanto, ser informado ao Grupo Mercado Comum, por intermédio da Secretaria 
Administrativa e tem o prazo de 15 dias, salvo acordo em contrário. Touscoz aponta que a maior parte dos conflitos internacionais resolvem-se pela diplomacia (NOHMI, 2005). Apenas em caso de não haver um consenso, a parte interessada pode, então, recorrer ao Grupo Mercado Comum, no prazo máximo de 60 dias. Atualmente, o Grupo tem 30 dias para fazer suas recomendações. Para isso, ele pode recorrer ao auxílio de especialistas. Os Estados, contudo, não estão vinculados a essa manifestação, podendo não acatar as sugestões. Além disso, atualmente, esta etapa não é senão optativa e pode, a critério do Estado demandante, se iniciar concomitantemente ao processo arbitral. Inovou-se, ademais, quanto à possibilidade de um Estado-membro não parte das negociações ter a faculdade de requerer que a matéria seja apreciada pelo Grupo.

Sucintamente, vale destacar algumas das mudanças trazidas pelo novo Protocolo: (i) criação de um Tribunal Permanente de Revisão, competente para revisar os laudos proferidos pelo Tribunal ad hoc; (ii) possibilidade de medidas de urgência e de caráter excepcional pelo Conselho Mercado Comum; (iii) adoção do princípio da proporcionalidade quando da aplicação de medidas compensatórias; (iv) a possibilidade do Estado-membro demandante escolher o sistema de controvérsias de outro foro, como o da OMC; (v) o regime de solicitação que se traduz na possibilidade de o Tribunal Permanente de Revisão emitir opiniões consultivas acerca do Direito de Integração; e (vi) a adoção do princípio da confidencialidade (NOHMI, 2005), comum nos sistemas arbitrais.

Sobre a arbitragem no Mercosul, importa destaca a observação feita por Moraes a cerca da "relativa diminuição do peso da decisão política no processo de resolução de diferendos; e (...) a criação de uma instância judicial permanente" (NOHMI, 2005, p. 103) com o advento do Protocolo de Olivos. O autor aponta que foi graças à criação de um órgão judicial permanente e a faculdade (não mais obrigatoriedade) da participação do Grupo Mercado Comum que essas mudanças foram possíveis (NOHMI, 2005). Além disso, deixou de ser encardo do Grupo e passou a ser tarefa da Secretaria Administrativa todas as gestões administrativas relativas à arbitragem. A formação do tribunal ad hoc dá-se, portanto, pela composição de três árbitros, como regra, dois deles nacionais dos Estados envolvidos e o terceiro de um terceiro Estado-membro. Os árbitros devem constar de uma lista prévia, para a qual cada Estado-membro contribui com o nome de doze árbitros nacionais e quatro não nacionais.

O Protocolo de Olivos manteve ainda regras importantes, como a escolha da lei aplicável; o procedimento cognitivo; a unificação da representação, quando há mais de dois Estados envolvidos; 
e o prazo para o cumprimento do laudo arbitral, que, quando não estabelecido pelo tribunal, será de trinta dias. Cabe lembrar que o prazo fica suspenso em caso de recurso ao Tribunal Permanente. Para tal recurso, tem-se o prazo de 15 dias e não poderá ser feito quando o tribunal ad hoc julgou com base na equidade - ex aequo et bono. Por fim, vale destacar a hipótese de o Tribunal Permanente funcionar como única instância, quando assim concordarem as partes. Este Tribunal é composto por cinco árbitros permanentes, cujos mandatos são de 2 anos para os árbitros escolhidos por cada Estado-membro e de três anos para o quinto árbitro, escolhido por consenso. Quando são dois os Estados envolvidos na controvérsia, o Tribunal funcionará apenas com três árbitros.

ICC

A International Chamber of Commerce - ICC é uma organização com sede em Paris, fundada em 1919, sem fins lucrativos regulado pela lei francesa e que lidera o network de comissões nacionais cujos membros são agentes econômicos e industriais (SCHÄFER; VERBIST; IMHOOS, 2005). Com uma estrutura semelhante à de uma organização internacional, a ICC possibilita o encontro de agentes econômicos, desvinculados de interesses governamentais, a fim de criarem normas comerciais que atendam as necessidades do mercado.

Este trabalho é feito através das comissões que, hoje, contam com mais de 500 membros, dentre os quais empresas e associações. Além das comissões, a ICC conta com um Conselho (semelhante a uma Assembléia Geral) composto por representantes de cada Comitê Nacional. Atualmente, a ICC está presente em cerca de 130 países, sendo que dez cadeiras do Conselho são destinadas aos representantes de países não membros. Além de propiciar debates e votar as propostas de normas uniformes, o Conselho elege o Presidente e o Vice-Presidente da organização, cujos mandados são de dois anos. O Secretariado Geral, por sua vez, exerce tarefas administrativas de modo a garantir que os programas sejam cumpridos.

Além do trabalho como fórum de criação de normas internacionais, a ICC exerce função importante junto a algumas organizações internacionais, tais como a ONU e a OMC. Nas cúpulas da ONU sobre desenvolvimento sustentável, a ICC atua como representante do empresariado; junto a UNCTAD, a ICC representa alguns dos países mais pobres, além de ter ajudado a criar o Conselho Consultivo de Investimentos. No âmbito da OMC, a ICC prepara recomendações empresariais de caráter mundial. 
A Comissão brasileira foi criada em 23 de outubro de 1967, com o objetivo de divulgar as práticas comerciais internacionais recomendadas pela ICC. Desta forma, "o ICC Brasil periodicamente promove reuniões das Comissões e de Grupos de Trabalho, seminários e workshops para tratar de importantes temas que afetam as relações comerciais do mundo" (PORTAL DO COMÉRCIO, 2010). No Brasil, conta-se com três comissões: a Comissão de Arbitragem, a Comissão do Desenvolvimento Sustentável e Energia e a Comissão de Propriedade Intelectual e Livre Concorrência.

Deste modo, o trabalho da ICC adquiriu grande importância no mercado internacional, pois mesmo se tratando de uma soft law, passou a ser adotada por diversos agentes do mercado, posto que se, por um lado, lhe falta coercitividade, por outro, lhe é reconhecida sua legitimidade e qualidade. Um exemplo é a regra de Incoterms que estabelecem as obrigações e os direitos no transporte de mercadorias e o seguro deste transporte entre o vendedor e o comprador em compras internacionais. Além disto, as regras de arbitragem da ICC têm sido adotadas por diversos contratos internacionais, dando ao Comitê sobre Arbitragem grande destaque.

Desde 1975, regras relativas à conciliação e a arbitragem de natureza comercial privadas vêm sendo editadas pela entidade. Em 2008, a Corte Internacional de Arbitragem da ICC atuou em 50 países, envolvendo árbitros de 74 diferentes nacionalidades (ICC, 2010).

Em seu website, a ICC disponibiliza dados estatísticos sobre sua atuação no mundo da arbitragem internacional que também servem para a aferição do crescimento da arbitragem, que, segundo analisado anteriormente, tem se expandido pelo mundo. A partir dessas estatísticas, Horacio A. Grigera Naon destaca que é crescente a participação dos países latino-americanos em arbitragens internacionais: em 1996, 11,5\% das partes envolvidas em casos da ICC eram latinoamericanos; enquanto, em 1987, este grupo era representado apenas por 3,8\% (GARCEZ, 1997).

\section{UNIDROIT}

O International Institute for the Unification of Private Law - UNIDROIT, fundado em 1926, tem por objetivo estudar os meios de harmonização e de coordenação do Direito Privado entre os Estados e de preparar gradualmente a adoção de uma legislação de Direito Privado uniforme (UNIDROIT, 2010). Inicialmente, o instituto era um órgão vinculado à Liga das Nações. No entanto, após o fim desta, em 1940, o UNIDROIT foi reestruturado. Hoje, é composto por 58 países membros (GDDC, 2010). 
Sua estrutura orgânica conta com um Secretariado, exercendo a função executiva; o Conselho que supervisiona os meios adotados pelo instituto e o trabalho do Secretariado e a Assembléia Geral, responsável por tomar decisões relativas ao orçamento, aos Programas de Trabalho (a cada três anos) e eleger o Conselho (a cada cinco anos).

Tendo em vista seus objetivos, os trabalhos do UNIDROIT são voltados, em regra, para a uniformização de normas materiais e não de conflito, a escolha de temas objeto de uniformização deve atender a certos critérios. Além disso, é mister que os Estados reconheçam a possibilidade de terem suas normas internas alteradas por normas internacionais naquela área específica, apesar de se tratar de normas não obrigatórias.

Para tanto, o instituto funciona segundo um método de trabalho que se divide em quatro passos:

(i) Uso dos Grupos de Estudo que auxiliam o Secretariado na elaboração de um relatório que visa a demonstrar a conveniência e a viabilidade de uma reforma legislativa nos diversos ordenamentos;

(ii) Negociação intergovernamental: Uma proposta deve ser aprovada pelo Conselho que deverá estabelecer os próximos passos;

(iii) Publicação do Material de Trabalho do Unidroit;

(iv) Cooperação com organizações internacionais: como resultado deste método e desta cooperação entre organizações internacionais, são inúmeros os exemplos de convenções internacionais preparadas pelo UNIDROIT e aprovada em Conferências que garantem, assim, obrigatoriedade ao texto aprovado: Convenção da Haia de 1964 sobre a formação de contratos de venda internacional de objetos mobiliários corpóreos e sobre a venda internacional de objetos mobiliários corpóreos; Convenção de Genebra de 1983 sobre a representação em matéria de venda internacional de mercadorias; Convenção de 1956 relativa ao contrato de transporte de mercadorias por estrada; e Convenção das Nações Unidas de 1980 sobre os contratos de venda internacional de mercadorias.

Um dos principais trabalhos elaborado por esta organização são os chamados Princípios Relativos aos Contratos Comerciais Internacionais do UNIDROIT. Segundo Lauro Gama, "os Princípios constituem uma fonte não-legislativa de direito uniforme dos contratos internacionais. Sua autoridade como fonte de direito, dentre outras razões, decorre pela excelência do trabalho realizado pelos juristas envolvidos em sua elaboração" (GAMA, 2006, p. 3). O autor conclui que os 
Princípios do UNIDROIT revelam uma leitura moderna dos contratos internacionais, em que a essência destes está na parceria entre as partes. Além disso, o autor vislumbra a arbitragem como forma de aplicação e difusão desses princípios (GAMA, 2006).

\section{ICSID}

O Centro Internacional de Resolução de Conflitos sobre Investimentos, em inglês, ICSID, foi criado no âmbito do Banco Mundial, através da Convenção para Solução de Disputas Relativas a Investimentos entre Estados e Cidadãos de Outros Estados, de 1966, com o objetivo de estabelecer um sistema de arbitragem voltado para conflitos entre investidores estrangeiros e Estados hospedeiros.

Esta Corte tem, hoje, 155 países signatários com mais de 180 casos já concluídos. Apesar de ser uma entidade com personalidade jurídica autônoma com relação ao Banco Mundial, em seu website fica clara a sua função político-econômica, quando se afirma que (ICSID, 2010):

The Convention sought to remove major impediments to the free international flows of private investment posed by non-commercial risks and the absence of specialized international methods for investment dispute settlement.

Importa deixar claro que o Centro tem um Conselho de Administração composto por representantes de todos os países-membros, além de um Painel de Conciliadores e Árbitros (GARCEZ, 1997). Em 1978, foi criado um novo mecanismo dentro do sistema de arbitragem da ICSID que permite a solução de controvérsias envolvendo um nacional ou um Estado não membro da Convenção, mediante ajuste entre as partes. Outra questão importante diz respeito ao fato de todo o procedimento arbitral da ICSID estar completamente desvinculado de uma lei nacional, inclusive, nas palavras de José Maria Rossani Garcez, a "designação do árbitro em revisão ou anulação da sentença arbitral, por exemplo, são confiadas não a um juiz inserido no sistema Judiciário estatal, mas ao próprio Centro" (GARCEZ, 1997, p. 181), que obriga o reconhecimento da sentença.

\section{A Lex Mercatoria}

Por fim, importa estudar o papel da lex mercatoria como forma de uniformização do Direito do Comércio Internacional, cuja importância é tal que, por vezes, se confundem. Antes de mais, 
importa, aqui, esclarecer uma questão conceitual importante: quando se faz referência à lex mercatoria, Irineu Strenger, o principal autor-base deste tópico, muitas vezes, utiliza tal expressão como sinônima de Direito do Comércio Internacional. Por esta mesma razão, assim será feito no presente trabalho. No entanto, cabe destacar que, apesar a história do Direito do Comércio Internacional evoluir conjuntamente com a lex mercatoria, posto que esta é um conjunto de regras fruto do comércio internacional, estes conceitos são distintos. Como foi visto, o Direito do Comércio Internacional conta com fontes internas estatais, como a lei, enquanto a lex mercatoria, como será estudado mais adiante, tem como principais fontes os costumes mercantis.

A lex mercatoria é resultado do questionamento de juristas sobre o fenômeno do comércio internacional. Tal conceito surge como referência aos costumes mercantis e logo ganha uma maior abrangência, tornando-se um grupo de normas próprias para o comércio internacional (STRENGER, 1996). Segundo Bernardo M. Cremades, a lex mercatoria consiste de quatro elementos: os usos comerciais, os contratos-tipos, a regulamentação profissional dada pela própria associação representativa e a jurisprudência arbitral (STRENGER, 1996). Irineu Strenger ensina que a elaboração destas normas visa a liberar o comércio dos entraves do Direito nacional e, por esta mesma razão, a doutrina destaca o princípio da autônoma da vontade como o princípio basilar de todo o Direito do Comércio Internacional.

Historicamente, foi na Idade Média, portanto, que surgiu um corpo de normas cujo objetivo era regular o comércio transfonterístico. Os costumes comerciais eram confirmados e recebiam tratamento legal através das cortes mercantis, em geral, formadas por membros da classe mercantil (STRENGER, 2005). Assim, como lembra Irineu Strenger, esse conjunto de regras, constituído exclusivamente para regular um grupo de pessoas e os institutos que lhes interessavam, passou a ser chamado de statuto mercartorum ou jus mercatorum (STRENGER, 2005).

Neste mesmo cenário, ocorriam as grandes feiras que uniam comerciantes de diversas cidades com diversos costumes. Com o fim de dirimir possíveis conflitos, instalava-se nas feiras uma corte responsável por qualquer conflito surgido da atividade mercantil, excepcionando questões relativas a terra. Essas cortes aplicavam a, então, chamada lex mercatoria.

Apesar de sua imensurável importância, após o período de surgimento, a lex mercatoria encontra-se em uma fase de declínio, com o fortalecimento do Estado-Nação e a imposição do Direito Nacional. Como visto, na Idade Média, os Estados europeus encontram-se enfraquecidos pelo poderio dos senhores feudais. No entanto, como a História ensina, é com o fortalecimento do 
comércio e da classe burguesa que o Estado-Nação retoma seu espaço. Neste contexto, surgem Estados, como Portugal, Espanha, Itália, etc. sob o poder monárquico e absolutista de seus reis. Deste modo, as relações comerciais internacionais deixam de ser reguladas pela lex mercatoria e passam a ser reguladas pelo Direito Nacional aplicável a cada caso.

Atualmente, a lex mercatoria volta a ganhar espaço com o grande desenvolvimento do mercado internacional, ainda que encontre limitações imposta pelo Direito Nacional (AMARAL, 2004). Nas palavras de Amilcar de Castro, é da natureza do comércio internacional o choque entre a lex mercatoria, traduzida no conceito de costume, e o Direito Nacional (CASTRO, 2000, p. 466):

o comércio internacional é essencialmente movimento, rapidez, dinamismo, migração de homens, circulação de mercadorias e de capital, fala Gannagé que esse movimento vem se chocar com a nação, entidade política e econômica que cada vez mais se organiza e se nacionaliza em face de outra, e por isso as regras que o governam devem ser, ao mesmo tempo, maleáveis, para não embaraçarem o movimento das transações internacionais, e firmes, para não sacrificarem o equilíbrio econômico da nação e a ordem interna.

Por esta razão, o que, hoje, se encontra no cenário internacional é a busca por um equilíbrio entre os dois corpos normativos de modo que, diante deste antagonismo entre o comércio internacional e a idéia de Estado-nação, o Direito encontre as soluções jurídicas capazes de conciliar os dois fenômenos, não apenas permitindo o desenvolvimento do mercado internacional, de forma que este siga o fluxo natural de seu dinamismo, mas inclusive estimulando-o e fortalecendo suas bases, sem se esquecer do equilíbrio econômico nacional, posto que o Estado deve se preservar diante de interesses externos, protegendo-se através de normas de polícia, Direito da Concorrência, entre outros meios.

Além da definição de Goldman transcrita acima, Irineu Strenger traz, ainda, outras muitas conceituações de lex mercatoria a fim de mostrar que seu conteúdo é de difícil delimitação, apesar de a doutrina reconhecer um mínimo comum, diferenciando-se apenas no ponto de vista adotado. A partir deste estudo, ele sintetiza, então, as diversas doutrinas em três correntes (STRENGER, 1996):

(i) Uma primeira que define a lex mercatoria como uma ordem jurídica autônoma, criada pelas partes envolvidas no caso concreto, independente do Direito. Esta, portanto, seria a corrente adotada por Loquin, para quem, a "la lex mercatoria est un nouvel ordre juridique, qui se forme au sein d'une communauté internationale d'hommes d'affaires et de commerçants suffisamment homogène et solidaire pour susciter la création de ces normes et en assurer l'application." Irineu 
Strenger extrai desta definição, por ele chamada de institucionalista e analítica, a precisa atividade desempenhada pela lex mercatoria (STRENGER, 1996, p. 77).

(ii) A segunda corrente entende que a lex mercatoria é, em verdade, um conjunto de normas consolidas e suficientes para a solução do caso concreto, substituindo o Direito aplicável. Segundo esta corrente, Irineu Strenger cita Langen que define a lex mercatoria como sendo "the rules of the game of international trade". Irineu Strenger entende que em tal definição está subentendido como a lex mercatoria tem a função de atuar em casos imprevisíveis, comuns na prática comercial internacional (STRENGER, 1996).

(iii) Por fim, a terceira corrente define a lex mercatoria como um complemento à lei nacional aplicável e um meio de consolidação dos usos e costumes mercantis.

Assim, o autor conclui que as definições mencionadas são amplas de modo que abrangem todas as diretrizes da lex mercatoria, inclusive destacando seu caráter internacional. Sendo esta última especialmente importante para a ênfase que a doutrina comumente dá ao princípio da autonomia da vontade no Direito do Comércio Internacional, devido ao fato de que o comércio internacional é baseado em princípios consagrados por todo o mundo, de modo que a diversidade de agentes não se torne um obstáculo para o seu desenvolvimento. O autor vai além e afirma que a diversidade de agentes é a própria base do princípio da autonomia. Ele conclui, ainda, que as definições, de modo geral, demonstram sempre certo grau de insatisfação com o Direito interno que, por sua vez, é visto como entrave para a solução de problemas comerciais no âmbito internacional. Por fim, percebe-se, através destas definições, que a lex mercatoria, por sua natureza, tem caráter metanacional, desvinculada de uma ordem jurídica nacional, possibilitando-se, assim, a liberdade de procedimentos visando a atender os anseios do comércio internacional. (STRENGER, 1996)

No que se refere às fontes da lex mercatoria, Irineu Strenger aponta para aquelas tradicionalmente citadas (como as cláusulas contratuais, os contratos-tipo, a jurisprudência arbitral e as normas emanadas de entidades especializadas), mas acrescenta a própria atividade comercial e o surgimento de novas tecnologias como criadores espontâneos de usos e regras. Por esta mesma razão, Irineu Strenger afirma que a lex mercatoria é, então, um processo em contínua elaboração (STRENGER, 1996).

Por fim, resta entender como a lex mercatoria deve ser aplicada por uma corte, quando lhe falta respaldo jurisdicional de um Estado. O que a doutrina afirma é que, apesar disso, a lex mercatoria tem força vinculativa. Irineu Strenger afirma que a lex mercatoria tem natureza "quase- 
legal". Esta força vinculativa advém do fato de que o Direito nacional não logra solucionar os conflitos que surgem no âmbito do comércio internacional, dentre outras razões, pelo fato de este evoluir com uma velocidade muito acima daquela com qual as leis internas evoluem (STRENGER, 1996). Por outro lado, a força vinculativa da lex mercatoria ganha reforço, visto que a evolução de suas regras nasce precisamente da atividade comercial e, por esta mesma razão, é reconhecida pelos agentes comerciais.

Assim sendo, a lex mercatoria, muitas vezes, é utilizada para preencher o vazio da lei aplicável. Mais comumente, verifica-se tal utilização em cortes arbitrais. Irineu Strenger, citando Lando, destaca que, ao aplicar a lex mercatoria, os árbitros terminam por encontrar menos divergências entre si (STRENGER, 1996).

Clarissa Brandão afirma, além disso, que é possível reconhecer a lex mercatoria como lei através da doutrina do Direito Reflexivo (ALVES, 2006). A autora explica que esta doutrina defende uma técnica de criação de Direito distinta daquela normalmente utilizada pelo Direito Positivo. Segundo essa doutrina, é possível reconhecer uma norma produzida por um sistema independente do Estado. Nas palavras de André-Nöel Roth: o direito reflexivo constitui um "direito procedente de negociações, de mesas redondas, etc., constitui uma tentativa para encontrar uma nova forma de regulação social, outorgando ao Estado e ao direito um papel de guia (e não de direção) da sociedade" (ALVES, 2006, p. 245). Isso porque, segundo a autora, o Estado e o Direito Positivo não acompanham a evolução social. Desta forma, pode-se dizer que a lex mercatoria, como forma de Direito Reflexivo, passaria a ser tratada como lei.

\section{Conclusão}

Apesar da análise crítica frente às múltiplas cortes arbitrais estudadas, bem como às organizações internacionais, poder-se-ia dizer que estas não representam uma fragmentação do sistema internacional arbitral, uma vez que nunca, de fato, houve um sistema universal. Desta forma, qualquer iniciativa, como as estudadas, representaria, portanto, um avanço importante no sentido da uniformização.

Neste sentido, não podemos deixar de ser otimistas e reconhecer tal avanço. O que se busca questionar neste trabalho, contudo, é que, juridicamente, o processo de uniformização pode trazer em si novas dificuldades frente às diversas legislações internacionais e aos órgãos internacionais que, em princípio, têm muitas de suas competências conflitantes. 
Por seu turno, a lex mercatoria é, portanto, tradução dos costumes profissionais do comércio internacional, e, senão o mais importante, um dos mais importantes modos de uniformização do Direito do Comércio Internacional, inclusive, em escala global e, de maneira espontânea.

Nesta linha, Irineu Strenger defende que a lex mercatoria será, em um futuro não muito distante, capaz de fornecer um sistema normativo pronto a enfrentar as divergências advindas do comércio internacional, até mesmo com uma jurisdição própria (STRENGER, 1996).

Neste sentido, verifica-se que o método conflitualista tem perdido espaço, em prol da criação de um corpo uniforme de normas que reflitam as peculiaridades do complexo e multi-disciplinador comércio internacional. A uniformização do Direito do Comércio Internacional é um processo natural, devido à sua dinâmica e ao seu desenvolvimento a passos largos, muito além da capacidade legislativa de um Estado-nação.

O que se pode concluir, portanto, é que mesmo multifacetário esse processo de uniformização ganha enorme importância frente às barreiras do Direito interno e dos Judiciários nacionais e, por isso, representa um avanço relevante para o comércio internacional que precisa acompanhar a dinâmica do atual estágio da globalização e, para isso, de normas globalmente reconhecidas, para se firmar.

\section{Referências}

ALVES, Clarissa Brandão Cardoso. Lex Petrolea. Revista Brasileira de Direito do Petróleo, Gás e Energia, 2006, v. 1. AMARAL, Antonio Carlos Rodrigues do (Coord.). Direito do comércio internacional: aspectos fundamentais. São Paulo: Aduaneiras, 2004.

AMBOS, Kai e Ana Cristina PAULO PEREIRA (coord.). Mercosul e União Européia: Perspectiva da Integração Regional. Rio de Janeiro: Lúmen Júris.

BAPTISTA, Luiz Olavo. O Mercosul, suas instituições e ordenamento jurídico. São Paulo: LTr, 1998. BORN, Gary B. International Commercial Arbitration: Commentary and Materials. 2 ed., Ardsley: Transnational Publishers, 2001.

BRONWLIE, Ian. Principles of Public International Law. 4 ed. Oxford: Oxford University Press, 1990. CAMPOS, João Mota (coord.). Organizações Internacionais: Teoria Geral. Lisboa: Calouste Gulbenkian, 1999.

CASELLA, Paulo B; ARAUJO, Nadia (Org.). Integração Jurídica Interamericana. São Paulo: LTr, 1998.

CASELLA, Paulo Borba. União Européia: instituições e ordenamento jurídico. São Paulo: LTr, 2002. 
CASELlA, Paulo Borba. Comunidade Européia e seu Ordenamento Jurídico. São Paulo: LTr, 1994. CASTRO, Amilcar de. Direito Internacional Privado. 5 ${ }^{\text {a }}$ ed. Rio de Janeiro, Forense, 2000.

DIREITO, Carlos Alberto Menezes; PEREIRA, Antonio Celso Alves; TRINDADE, Antônio Augusto Cançado. Novas perspectivas do Direito Internacional Privado Contemporâneo. Rio de Janeiro: Renovar, 2008.

DINH, Nguyen Q.; DAILLIER, Patrick; PELLET, Alain. Droit International Public. Tradução de Vítor Marques Coelho. 2 ed. Lisboa: LGDJ, 2003. DOLINGER, Jacob. Direito e o Amor. Rio de Janeiro: Renovar, 2009.

DOLINGER, Jacob. Direito Internacional Privado: Parte Geral. 9 ed. Rio de Janiero: Renovar, 2009.

DOLINGER, Jacob; TIBURCIO, Carmen. Direito Internacional Privado: Arbitragem Comercial Internacional. Rio de Janeiro: Renovar, 2003.

FELIX, Ana Cristina Azevedo de Carvalho. A Solução de Controvérsias na OMC. In Prim@ Facie, ano 1, n. 1, jul./dez. 2002.

FRANCA FILHO, Marcílio Toscano. Introdução ao Direito Comunitário. São Paulo: Juarez de Oliveira, 2002.

GARCEZ, José Maria Rossani (coord.). A Arbitragem na era da globalização. Rio de Janeiro: Forense, 1999. GAMA, Lauro. Contratos Internacionais à luz dos princípios do UNIDROIT 2004: soft law, arbitragem e jurisdição. Rio de Janeiro: Renovar, 2006. GDDC, http://www.gddc.pt/cooperacao/materia-civil-comercial/unidroit.html, acesso em 04 de fevereiro de 2010. ICC. Disponível em http://www.iccwbo.org/court/arbitration/id5256/index.html. Acesso em 25 de maio de 2010. ICSID. Disponível em http://icsid.worldbank.org. Acesso em 25 de maio de 2010 .

KELLY, Claire. The Politics of International Economic Law: Legitimacy and the UNCITRAL Working Methods. Brooklyn: Brooklyn Law School, mar. 2009.

LOBO, Maria Teresa de Cárcomo. Manual de Direito Comunitário. Curitiba: Juruá, 2001.

LUPI, André Lipp Pinto Basto. Soberania, OMC e Mercosul. São Paulo: Aduaneiras, 2001.

MAXEINER, James R., Why are U.S. Lawyers Not Learning from Comparative Law? The International Practice of Law: Liber Amicorum for Thomas Bär and Robert Karrer, Nedin Peter Vogt, et al., eds., London \& Boston: Kluwer Law International, 1997.

MELlo, Celso D. de Albuquerque. Curso de Direito Internacional Público. 10 ed. Rio de Janeiro: Renovar, 1994. 
MELLO, Celso D. de Albuquerque. Direito Internacional da Integração. Rio de Janeiro: Renovar, 1996.

NOHMI, Antônio Marcos. Arbitragem Internacional: Mecanismos de solução de conflitos entre Estados. Belo Horizonte: Del Rey, FCH-FUMEC, 2005.

NOTTAGE, Luke R. The Procedural Lex Mercatoria: The Past, Present and Future of International Commercial Arbitration. Syney: Sydney Law School Research, 2006. OMC. Disponível em: http://www.wto.org/. Acesso em 25 de maio de 2010.

OMC, Caso dos “Camarões e Tartarugas”, WT/DS58/AB/R, 12 de outubro de 1998. PORTAL DO

http://www.portaldocomercio.org.br/cgi/cgilua.exe/sys/start.htm?tpl=section_tpl28.htm\&sid=192. Acesso 9/05/2010.

REZEK, José Francisco. Direito Internacional Público: curso elementar. 2 ed. São Paulo: Saraiva, 1991.

RIBEIRO, Marilda Rosado de Sá. Direito do Petróleo: as Joint Ventures na indústria do Petróleo. 2a. ed. Rio de Janeiro: Renovar, 2003.

SCHÄFER, Erik; VERBIST, Herman; IMHOOS, Christophe. ICC Arbitration In Practice. The Hague: Kluwer Law International: 2005.

STRENGER, Irineu. Direito Internacional Privado. São Paulo: LTr, 8ªed, 2005.

STRENGER, Irineu. Direito do comércio internacional e lex mercatoria. São Paulo: Ltr, 1996.

TENÓRIO, Oscar. Direito Internacional Privado. 11 ed, ver e atual. Rio de Janeiro: Freitas Bastos, 1976. TOSTES, Ana Paula B. União Européia: o poder político do direito. Rio de Janeiro: Renovar, 2004.

UE, http://www.europarl.europa.eu/parliament/public/staticDisplay.do;jsessionid=C058EF08C33189758 FBC96E6DBB6377E.node1?id=146\&language=pt, acesso em 03 de fevereiro de 2010.

UNCITRAL, France's Observations on UNCITRAL's Working Methods, § 1, U.N. Doc. A/CN.9/635 (May 24, 2007). UNIDROIT, http://www.unidroit.org/dynasite.cfm?dsmid=84219, acesso em 04 de fevereiro de 2010. 